\title{
SARS-COV-2 Presenting as New Onset Atrial Fibrillation: A Case Report
}

\author{
Jason Harhay $^{1}$, Muniba Khan ${ }^{1}$, Shalin Shah ${ }^{2}$, Amit Malhotra ${ }^{1}$ \\ 1. Internal Medicine, Buffalo General Medical Center, University at Buffalo, Buffalo, USA 2. Internal Medicine, \\ University at Buffalo, Buffalo, USA
}

Corresponding author: Jason Harhay, jharhay@buffalo.edu

\begin{abstract}
Current literature has documented numerous different presentations of SARS-COV-2 (COVID-19). Common symptoms include fever, cough and shortness of breath, however, lack of these symptoms does not exclude COVID-19. Given the incomplete understanding of the virus at this time, healthcare professionals must continue to remain informed of the vast number of clinical presentations of the virus to ensure early supportive treatment, ideally leading to improved outcomes.
\end{abstract}

Categories: Cardiology, Internal Medicine, Infectious Disease

Keywords: sars-cov-2, covid 19, atrial fibrillation, altered mental status

\section{Introduction}

The typical presentation of SARS-COV-2 (COVID-19) is fever, cough, tachypnea and shortness of breath [1]. However, with time, many other presentations have been documented, likely owing to an incomplete understanding of this new pathogen. To help inform the growing knowledge base, we present a patient with no documented past medical history who presented with new onset atrial fibrillation, pulmonary edema, and altered mental status.

The primary objective of this case report is to present an atypical presentation of the SARS-COV-2 virus.

\section{Case Presentation}

A 90-year-old African American female with no documented past medical history presented to the emergency department following a welfare check from Adult Protective Services. The patient was noted to have altered mentation by emergency medical services (EMS). In the emergency room, vitals demonstrated a temperature of 97.9 , blood pressure of $141 / 78$, heart rate of 140 , and a respiratory rate of 24 not requiring oxygen supplementation. Physical exam was notable for tachycardia with irregularly irregular rhythm and mild bibasilar crackles with no jugular venous distention or lower extremity edema. The patient was found

Received 04/30/2020 Review began 05/04/2020 Review ended 05/05/2020 Published 05/11/2020

๑) Copyright 2020 Harhay et al. This is an open access article distributed under the terms of the Creative Commons Attribution License CC-BY 4.0., which permits unrestricted use, distribution, and reproduction in any medium, provided the original author and source are credited. to be in atrial fibrillation with a rapid ventricular response (afib with RVR) on initial EKG (Figure 1). Chest Xray revealed diffuse pulmonary edema and hazy opacities (Figure $2 \mathrm{~A}$ ). Repeat chest X-ray following diuresis demonstrated bilateral interstitial infiltrates (Figure 2B). CT scan of the chest without IV contrast demonstrated multiple regions of ground-glass opacities (Figure 2C-2E). Labs revealed a sodium of 147, anion gap of 23 , lactic acid level of 4.3 , and pro-B-natriuretic peptide was 1637 . Initial venous blood gas (VBG) demonstrated pH of 7.47 with pCO2 of 34 . Additionally, troponins were negative over three blood draws. An echocardiogram revealed an ejection fraction of 65-70\% with grade 1 diastolic dysfunction. 


\section{Cureus}

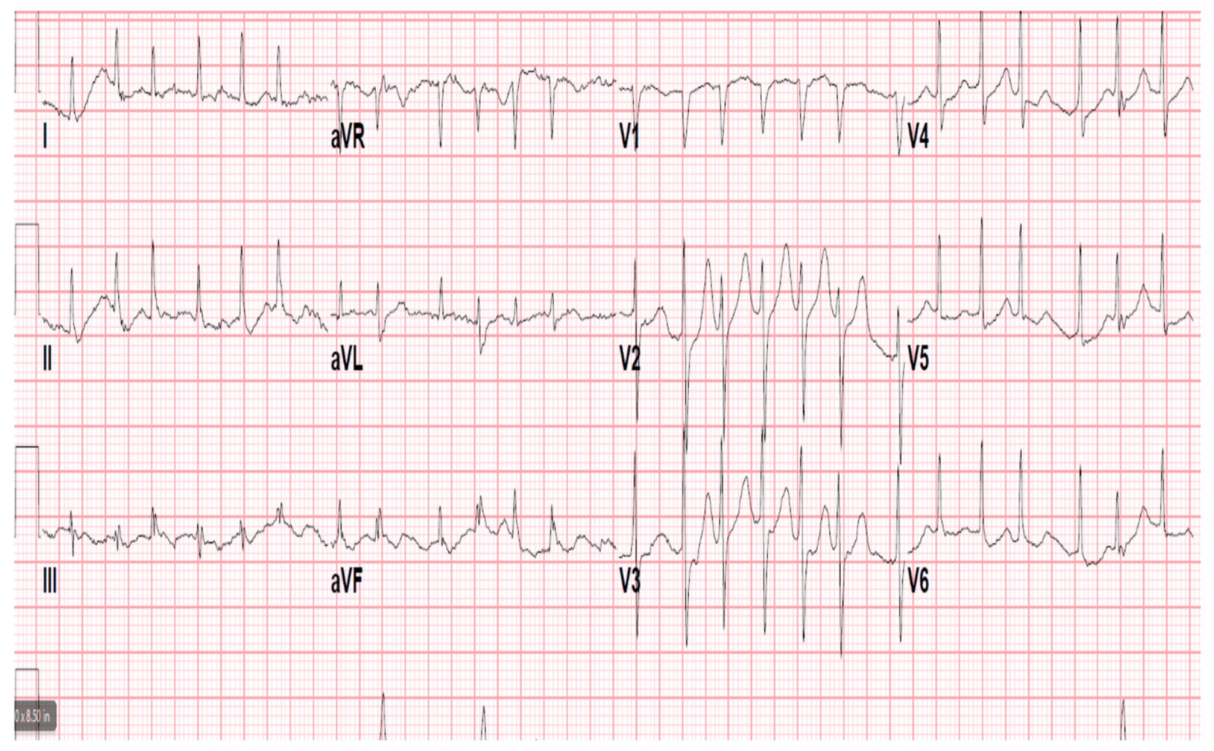

FIGURE 1: Atrial Fibrillation with Rapid Ventricular Response

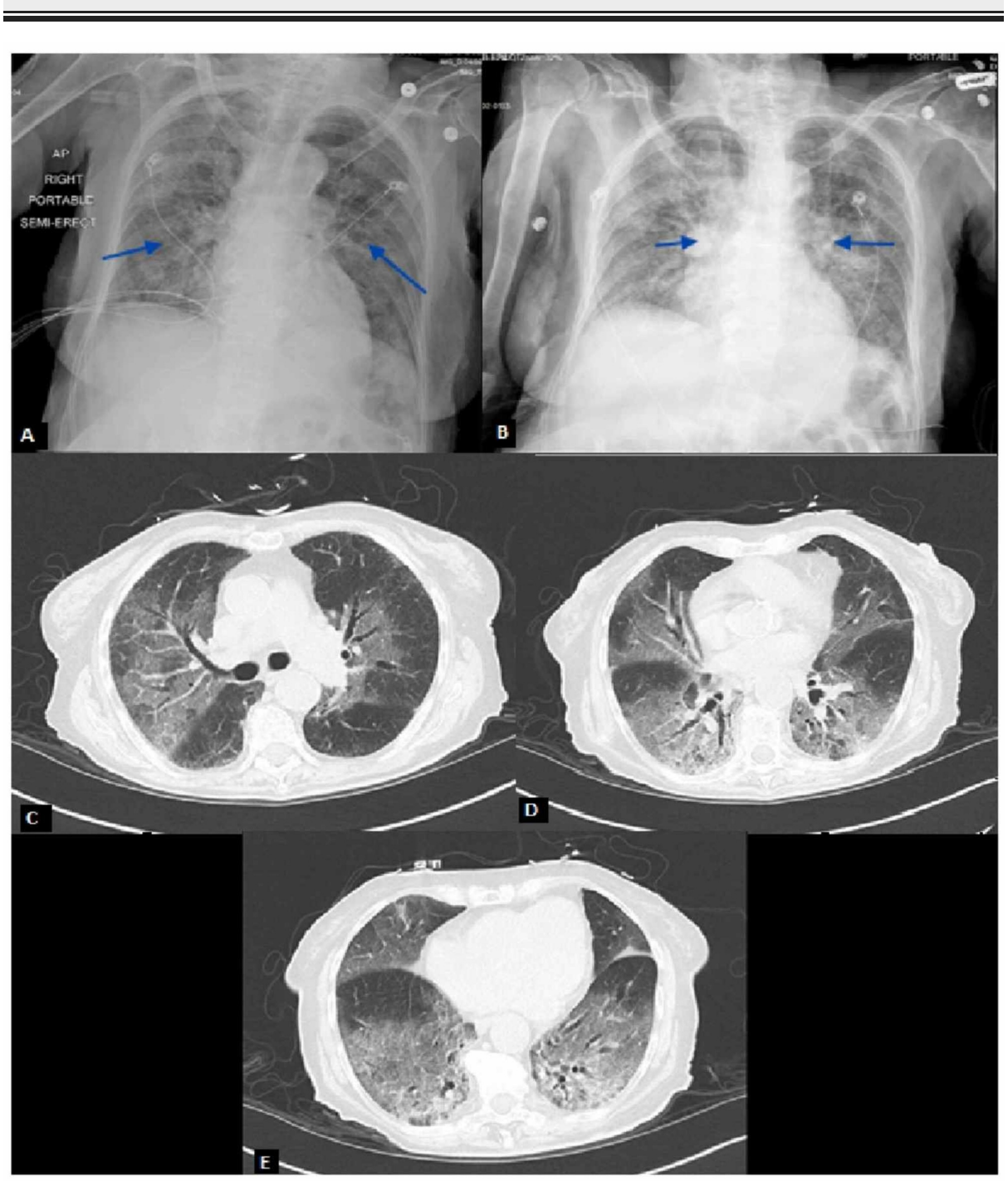

FIGURE 2: Chest X-Rays and CT Scan Demonstrating Bilateral Pulmonary Infiltrates

(A) Hazy appearance of the lung fields with scattered airspace opacities. (B) Bilateral faint patchy airspace 
Given the patient's imaging, COVID-19 polymerase chain reaction (PCR) testing was performed with a positive result on day three of hospitalization. That same day, the patient rapidly deteriorated and became hypoxic prompting intubation and vasopressor support. The patient was treated with supportive care in the intensive care unit (ICU) and was started on hydroxychloroquine and azithromycin. She was extubated on day nine of admission.

\section{Discussion}

Since the onset of COVID-19, a number of presentations have been documented. The typical presentation includes symptoms of fever, cough, and shortness of breath. However, these symptoms are not always seen on the initial presentation. As a result, suspicion for this viral infection may erroneously become lower on the differential diagnosis. As noted in our case presentation, the patient presented with altered mental status and afib with RVR. A study published in "Heart Rhythm" suggested that atrial fibrillation can be induced by a systemic inflammatory response and increased sympathetic tone [2]. The study focused on influenza; however, other viral and bacterial infections can result in atrial fibrillation, particularly in sepsis patients.

Sinus tachycardia (the most common arrhythmia in COVID-19 patients to date), myocardial injury, hypotension, bradycardia, and transient cardiomegaly have been documented as complications of SARS, particularly in patients with underlying cardiovascular disease [3-5]. Current literature has proposed the viral involvement of cardiomyocytes and systemic inflammation as the mechanism of myocardial injury [4]. Few other explanations have been provided for cardiovascular involvement. It is possible that the proposed systemic inflammation involved in myocardial injury induces increased sympathetic tone which would provide an explanation as to why some COVID-19 patients develop arrhythmias.

\section{Conclusions}

New manifestations of COVID-19 are being documented on a daily basis. Our patient's initial presentation resulted in decreased initial suspicion for COVID-19 infection given the lack of typical signs and symptoms. As the literature grows, earlier testing and diagnosis will follow ultimately leading to better outcomes. Further research and data collection will be necessary to develop a better understanding of the underlying mechanisms and clinical outcomes involved with the manifestations of COVID-19.

\section{Additional Information \\ Disclosures}

Human subjects: Consent was obtained by all participants in this study. Conflicts of interest: In compliance with the ICMJE uniform disclosure form, all authors declare the following: Payment/services info: All authors have declared that no financial support was received from any organization for the submitted work. Financial relationships: All authors have declared that they have no financial relationships at present or within the previous three years with any organizations that might have an interest in the submitted work. Other relationships: All authors have declared that there are no other relationships or activities that could appear to have influenced the submitted work.

\section{References}

1. Richardson S, Hirsch JS, Narasimhan M, et al.: Presenting characteristics, comorbidities, and outcomes among 5700 patients hospitalized with COVID-19 in the New York City Area. JAMA. 2020, [Published online ahead of print]:10.1001/jama.2020.6775

2. Chang TY, Chao TF, Liu CJ, et al.: The association between influenza infection, vaccination, and atrial fibrillation: a nationwide case-control study. Heart Rhythm. 2016, 13:1189-1194. 10.1016/j.hrthm.2016.01.026

3. Madjid M, Safavi-Naeini P, Solomon SD, Vardeny O: Potential effects of coronaviruses on the cardiovascular system: a review. JAMA Cardiol. 2020, [Published online ahead of print]: 10.1001/jamacardio.2020.1286

4. Yu C, Wong RS, Wu EB, et al.: Cardiovascular complications of severe acute respiratory syndrome . Postgrad Med J. 2006, 82:140-144. 10.1136/pgmj.2005.037515

5. Kochi AN, Tagliari AP, Forleo GB, Fassini GM, Tondo C: Cardiac and arrhythmic complications in patients with Covid-19. J Cardiovasc Electrophysiol. 2020, 31:1003-1008. 10.1111/jce.14479 